\title{
Mapping out a future for ungulate migrations
}

Authors: Matthew J. Kauffman ${ }^{1}$, Francesca Cagnacci ${ }^{2}$, Simon Chamaillé-Jammes ${ }^{3,4,5}$, Mark Hebblewhite ${ }^{6}$, J. Grant C. Hopcraft ${ }^{7}$, Jerod A. Merkle ${ }^{8}$, Thomas Mueller ${ }^{9,10}$, Atle Mysterud ${ }^{11}$, Wibke Peters ${ }^{12}$, Christiane Roettger ${ }^{13}$, Alethea Steingisser ${ }^{14}$, James E. Meacham ${ }^{14}$, Kasahun Abera $^{15}$, Jan Adamczewski ${ }^{16}$, Ellen O. Aikens ${ }^{17,18,19}$, Carly Vynne ${ }^{20}$, Hattie Bartlam-Brooks ${ }^{21}$, Emily Bennitt ${ }^{22}$, Joel Berger ${ }^{23,24}$, Charlotte Boyd ${ }^{25}$, Steeve D. Côté26, Lucie Debeffe ${ }^{27}$, Nandintsetseg Dejid ${ }^{9}$, Emiliano Donadio ${ }^{28}$, Luthando Dziba ${ }^{29}$, William F. Fagan ${ }^{30}$, Claude Fischer $^{31}$, Stefano Focardi ${ }^{32}$, John Fryxell ${ }^{33}$, Richard W.S. Fynn ${ }^{22}$, Chris Geremia ${ }^{34}$, Benito A. González $^{35}$, Anne Gunn ${ }^{36}$, Elie Gurarie ${ }^{30}$, Marco Heurich ${ }^{37,38}$, Jodi Hilty ${ }^{39}$, Mark Hurley ${ }^{40}$, Aran Johnson $^{41}$, Kyle Joly ${ }^{42}$, Petra Kaczensky ${ }^{43,44}$, Corinne J. Kendall ${ }^{45}$, Pavel Kochkarev ${ }^{46}$, Leonid Kolpaschikov $^{47}$, Rafał Kowalczyk ${ }^{48}$, Frank van Langevelde ${ }^{49}$, Binbin Li ${ }^{50}$, Alex L. Lobora ${ }^{51}$, Anne Loison ${ }^{52}$, Tinaapi H. Madiri ${ }^{53}$, David Mallon ${ }^{54,55}$, Pascal Marchand ${ }^{56}$, Rodrigo A. Medellin $^{13,57}$, Erling Meisingset ${ }^{58}$, Evelyn Merrill ${ }^{59}$, Arthur D. Middleton ${ }^{60}$, Kevin L. Monteith ${ }^{61}$, Malik Morjan $^{62,63}$, Thomas A. Morrison ${ }^{7}$, Steffen Mumme ${ }^{2,64}$, Robin Naidoo ${ }^{65}$, Andres Novaro ${ }^{66}$, Joseph O. Ogutu $^{67}$, Kirk A. Olson ${ }^{68}$, Alfred Oteng-Yeboah ${ }^{13,69}$, Ramiro J.A. Ovejero ${ }^{70,71}$, Norman Owen-Smith ${ }^{72}$, Antti Paasivaara ${ }^{73}$, Craig Packer ${ }^{74}$, Danila Panchenko ${ }^{75}$, Luca Pedrotti ${ }^{76}$, Andy Plumptre ${ }^{77}$, Christer M. Rolandsen ${ }^{43}$, Sonia Said ${ }^{78}$, Albert Salemgareyev ${ }^{79}$, Aleksandr Savchenko ${ }^{80}$, Piotr Savchenko ${ }^{80}$, Hall Sawyer ${ }^{81}$, Moses Selebatso ${ }^{82}$, Matthew Skroch ${ }^{83}$, Erling Solberg $^{43}$, Jared A. Stabach ${ }^{84}$, Olav Strand ${ }^{43}$, Michael J. Suitor ${ }^{85}$, Yasuyuki Tachiki ${ }^{86}$, Anne Trainor $^{87}$, Arnold Tshipa ${ }^{88,89}$, Munir Z. Virani ${ }^{90}$, Stephanie Ward ${ }^{91}$, George Wittemyer ${ }^{23}$, Wenjing $\mathrm{Xu}^{60}$, Steffen Zuther ${ }^{91}$

\section{Affiliations:}

${ }^{1}$ U.S. Geological Survey, Wyoming Cooperative Fish and Wildlife Research Unit, Department of Zoology and Physiology, University of Wyoming, Laramie, WY 82071, USA.

${ }^{2}$ Department of Biodiversity and Molecular Ecology, Research and Innovation Centre, Fondazione Edmund Mach, 38010 San Michele all'Adige, Italy.

${ }^{3}$ CEFE, Univ Montpellier, CNRS, EPHE, IRD, Univ Paul Valéry Montpellier 3, Montpellier, France.

${ }^{4}$ Department of Zoology \& Entomology, Mammal Research Institute, University of Pretoria, Pretoria, South Africa.

${ }^{5}$ LTSER France, Zone Atelier "Hwange”, Hwange National Park, Bag 62, Dete, Zimbabwe.

${ }^{6}$ Wildlife Biology Program, Department of Ecosystem and Conservation Sciences, Franke College of Forestry and Conservation, University of Montana, Missoula, MT, 59812, USA.

${ }^{7}$ Boyd Orr Centre for Population and Ecosystem Health, Institute of Biodiversity, Animal Health \& Comparative Medicine (IBAHCM), University of Glasgow, G12 8QQ, UK.

${ }^{8}$ Department of Zoology and Physiology, University of Wyoming, Laramie, WY, 82071, USA.

${ }^{9}$ Senckenberg Biodiversity and Climate Research Centre, Senckenberg Gesellschaft für Naturforschung, Senckenberganlage 25, 60325 Frankfurt (Main), Germany. 
${ }^{10}$ Department of Biological Sciences, Goethe University Frankfurt, 60323 Frankfurt (Main), Germany.

${ }^{11}$ Centre for Ecological and Evolutionary Synthesis, Department of Biosciences, University of Oslo, P.O. Box 1066 Blindern, NO-0316 Oslo, Norway.

${ }^{12}$ Bavarian State Institute of Forestry, Department for Conservation, Biodiversity and Wildlife Management, 85354 Freising, Germany.

${ }^{13}$ Secretariat of the Convention on the Conservation of Migratory Species of Wild Animals (CMS), 53113 Bonn, Germany.

${ }^{14}$ InfoGraphics Lab, Department of Geography, University of Oregon, Eugene, OR, 97403, USA.

${ }^{15}$ German Technical Cooperation (GIZ), Biodiversity and Forestry Programme in Ethiopia. Addis Ababa, Ethiopia.

${ }^{16}$ Wildlife Division, Environment and Natural Resources, Government of Northwest Territories, Yellowknife, NT, X1A 2L9 Canada.

${ }^{17}$ Department of Migration, Max Planck Institute of Animal Behavior, 78315 Radolfzell, Germany.

${ }^{18}$ Department of Biology, University of Konstanz, 78457 Konstanz, Germany.

${ }^{19}$ Centre for the Advanced Study of Collective Behaviour, University of Konstanz, 78468 Konstanz, Germany.

${ }^{20}$ Osprey Insights, Seattle, WA, 98115, USA.

${ }^{21}$ Structure and Motion Laboratory, The Royal Veterinary College, Hatfield AL9 7TA, UK.

${ }^{22}$ Okavango Research Institute, University of Botswana, Maun, Botswana.

${ }^{23}$ Department of Fish, Wildlife and Conservation Biology, Colorado State University, Fort Collins, CO 80523, USA.

${ }^{24}$ Wildlife Conservation Society, Bronx, New York, 10460, USA.

${ }^{25}$ International Union for Conservation of Nature (IUCN), North America Office, Washington, DC 20009, USA.

${ }^{26}$ Département de biologie, Caribou Ungava \& Centre d'études nordiques, Université Laval, Québec (QC), G1V 0A6, Canada.

${ }^{27}$ Université de Toulouse, INRAE, CEFS, F-31326, Castanet-Tolosan, France.

${ }^{28}$ Fundación Rewilding Argentina, Estancia La Ascensión, Los Antiguos, Santa Cruz 9041, Argentina.

${ }^{29}$ Conservation Services, South African National Parks, Pretoria, 0001, South Africa; Centre for African Conservation Ecology, Nelson Mandela University, Port Elizabeth, South Africa

${ }^{30}$ Department of Biology, University of Maryland, MD, 20742, USA.

${ }^{31}$ University of Applied Sciences of Western Switzerland, Department of Nature Management, 1274, Jussy, Switzerland.

${ }^{32}$ Istituto dei Sistemi Compless del CNR, 50019 Sesto Fiorentino, Italy. 
${ }^{33}$ Department of Zoology, Biodiversity Institute of Ontario (BIO), Center for Biodiversity Genomics, University of Guelph, Guelph, Ontario N1G 2WI, Canada.

${ }^{34}$ Yellowstone Center for Resources, Yellowstone National Park, Mammoth Hot Springs, WY 82190, USA.

${ }^{35}$ Laboratorio de Ecología de Vida Silvestre, Facultad de Ciencias Forestales y de la Conservación de la Naturaleza, Universidad de Chile, Santiago, Chile.

${ }^{36}$ Circum-Arctic Rangifer Monitoring and Assessment, Salt Spring Island, British Columbia, V8K 1V1, Canada.

${ }^{37}$ Department of Visitor Management and National Park Monitoring, Bavarian Forest National Park, 94481, Grafenau, Germany.

${ }^{38}$ Chair of Wildlife Ecology and Management, Albert Ludwigs University Freiburg, 79106, Freiburg, Germany.

${ }^{39}$ Yellowstone to Yukon Conservation Initiative, Canmore, AB T1W 1P6, Canada.

${ }^{40}$ Idaho Department of Fish and Game, Boise, ID, 83712, USA.

${ }^{41}$ Southern Ute Indian Tribe, Division of Wildlife Resource Management, Ignacio, CO, 81137 USA.

${ }^{42}$ Gates of the Arctic National Park and Preserve, Arctic Inventory and Monitoring Network, National Park Service, Fairbanks, Alaska, 99709, USA.

${ }^{43}$ Norwegian Institute for Nature Research (NINA), NO-7485, Trondheim, Norway.

${ }^{44}$ Research Institute of Wildlife Ecology, University of Veterinary Medicine, Vienna, Austria.

${ }^{45}$ North Carolina Zoo Department of Conservation, Education, and Science, 4401 Zoo Parkway, Asheboro, NC, 27205, USA.

${ }^{46}$ Central Siberia Nature Reserve "Tsentralnosibirsky", Krasnoyarsk Krai, 648368, Russia.

${ }^{47}$ Federal State Budgetary Institution "Reserves of Taimyr", Norilsk, 663305, Russia.

${ }^{48}$ Mammal Research Institute, Polish Academy of Sciences, 17-230 Białowieża, Poland.

${ }^{49}$ Wildlife Ecology and Conservation Group, Wageningen University and Research, 6708 PB Wageningen, The Netherlands.

${ }^{50}$ Environmental Research Centre, Duke Kunshan University, Kunshan, Jiangsu, 215316, China.

${ }^{51}$ Directorate of Research Development and Coordination, Tanzania Wildlife Research Institute, P.O Box 661, Arusha, Tanzania.

${ }^{52}$ Univ. Grenoble Alpes, Univ. Savoie Mont Blanc, CNRS, LECA, Grenoble, France.

${ }^{53}$ Zimbabwe Parks and Wildlife Management Authority, Hwange National Park, Zimbabwe.

${ }^{54}$ Department of Natural Sciences, Manchester Metropolitan University, Manchester M1 5GD, UK.

${ }^{55}$ IUCN Species Survival Commission, Gland, Switzerland. 
${ }^{56}$ Office Français de la Biodiversité, Direction de la Recherche et de l'Appui Scientifique, Unité Ongules Sauvages, "Les portes du Soleil", F-34990 Juvignac, France.

${ }^{57}$ Instituto de Ecología, Universidad Nacional Autónoma de México (UNAM), 04510 Mexico City, Mexico.

${ }^{58}$ Department of Forestry and Forestry resources, Norwegian Institute of Bioeconomy Research, NO-6630, Tingvoll, Norway.

${ }^{59}$ Department of Biological Sciences, University of Alberta, Edmonton, AB T6G 1Z8, Canada.

${ }^{60}$ Department of Environmental Science, Policy, and Management, University of California, Berkeley, Berkeley, CA 94709, USA.

${ }^{61}$ Haub School of Environment and Natural Resources, Wyoming Cooperative Fish and Wildlife Research Unit, Department of Zoology and Physiology, University of Wyoming, Laramie, WY 82072, USA.

${ }^{62}$ Ministry of Wildlife Conservation and Tourism, Jebel Lemon, Juba, South Sudan.

${ }^{63}$ Department of Environmental Studies, School of Natural Resources and Environmental Studies University of Juba, Juba, South Sudan.

${ }^{64}$ Department of Biology and Biotechnologies “Charles Darwin”, University of Rome La Sapienza, 00185 Rome, Italy.

${ }^{65}$ WWF-US, 1250 24th Street NW, Washington, DC, 20037, USA.

${ }^{66}$ Instituto de Investigaciones en Biodiversidad y Medioambiente (INIBIOMA)-Consejo Nacional de Investigaciones Científicas (CONICET)-Universidad del Comahue and Wildlife Conservation Society-Argentina, 8371 Neuquén, Argentina.

${ }^{67}$ Biostatistics Unit, Institute of Crop Science, University of Hohenheim, 70599 Stuttgart, Germany.

${ }^{68}$ Wildlife Conservation Society, Mongolia Country Program, Ulaanbaatar-14200, Mongolia.

${ }^{69}$ Council for Scientific and Industrial Research - Ghana, Wildlife Division, Forestry Commission of Ghana, Accra, Ghana.

${ }^{70}$ Instituto de Ecología Regional (IER), Universidad Nacional de Tucumán (UNT)-Consejo Nacional de Investigaciones Científicas (CONICET), CCT-CONICET-TUCUMAN, Tucumán, Argentina.

${ }^{71}$ Laboratorio de Ecología Conductual, Instituto de Ciencias Ambientales y Evolutivas, Facultad de Ciencias; Universidad Austral de Chile (UACH)-Comisión Nacional de Investigación Científica y Tecnológica (CONICYT), Valdivia, Chile.

${ }^{72}$ Centre for African Ecology, School of Animal, Plant and Environmental Sciences, University of the Witwatersrand, Wits, 2050 South Africa.

${ }^{73}$ Natural Resources Institute Finland, FI-00790, Helsinki, Finland.

${ }^{74}$ Department of Ecology, Evolution, and Behavior, University of Minnesota, St. Paul, MN 55108, USA. 
${ }^{75}$ Institute of Biology of the Karelian Research Centre of the Russian Academy of Sciences, 185910 Petrozavodsk, Russia.

${ }^{76}$ Stelvio National Park, 23032 Bormio (SO), Italy.

${ }^{77}$ Key Biodiversity Area Secretariat, BirdLife International, Cambridge CB2 3QZ, UK.

${ }^{78}$ Office Français de la Biodiversité, Direction de la Recherche et de l'Appui Scientifique, "Montfort", 01330 Birieux, France.

${ }^{79}$ Association for the Conservation of Biodiversity of Kazakhstan (ACBK), Nur-Sultan, 010000 Kazakhstan.

${ }^{80}$ Department of Wildlife Resource Studies and Reserve Management, Institute of Ecology and Geography, Siberian Federal University, 660041, Krasnoyarsk, pr. Svobodnyi, Russia.

${ }^{81}$ Western EcoSystems Technology, Inc., Laramie, WY, 82072, USA.

${ }^{82}$ Kalahari Research and Conservation Trust, Gaborone, Botswana.

${ }^{83}$ The Pew Charitable Trusts, Portland, OR, 97201, USA.

${ }^{84}$ Smithsonian National Zoo \& Conservation Biology Institute, Conservation Ecology Center, Front Royal, VA 22630, USA.

${ }^{85}$ Fish and Wildlife Branch, Environment Yukon, Government of Yukon, Dawson City, Yukon, Y0B 1G0, Canada.

${ }^{86}$ Rakuno Gakuen University, 069-8501 Ebetsu, Hokkaido, Japan.

${ }^{87}$ The Nature Conservancy, Africa Program, Cincinnati, OH 45221, USA.

${ }^{88}$ Wilderness Safaris, Victoria Falls, Zimbabwe.

${ }^{89}$ Department of Forestry Resources and Wildlife Management, National University of Science and Technology, Ascot, Bulawayo, Zimbabwe.

${ }^{90}$ The Peregrine Fund, Boise, ID 83709, USA.

${ }^{91}$ Frankfurt Zoological Society, Altyn Dala Conservation Initiative, 60316 Frankfurt am Main, Germany.

*Correspondence to: mkauffm1@uwyo.edu. 


\section{Main Text:}

Wildebeest, 1.3 million strong, plod steadily across the Serengeti plains, chasing the recent rains. Hundreds of thousands of caribou crisscross the Arctic, their hooves pounding across the vast tundra. A mule deer doe pauses along her two-month march to nibble the green grass of spring before rejoining a well-worn trail through the sagebrush. The migrations of ungulates (hooved mammals) are some of the most impressive phenomena in the animal kingdom. And while millions of people have observed some of these journeys, such as the wildebeest migration, animal tracking studies are discovering new ungulate migrations that surprise scientists and the public alike.

Migration is a fundamental ecological process that promotes abundant herds (1), whose biomass cascades up and down terrestrial food webs. Migratory ungulates provide the prey base that maintains large carnivore and scavenger populations and underpins terrestrial biodiversity. When ungulates move in large aggregations, their hooves, feces and urine create conditions that facilitate unique biotic communities (2). The phenomenon of migration thus provides a wealth of ecosystem services, while also supporting indigenous people and local communities on many continents. More than just using them for food and clothing, humans have been culturally linked to and sustained by migratory ungulates for thousands of years.

Despite their importance, ungulate migrations are disappearing at an alarming rate (3). Without a strategic and collaborative effort, many of the world's great migrations will continue to be truncated, severed, or lost in the coming decades. Fortunately, an evidence-based alternative exists. A combination of indigenous knowledge, historical records, animal tracking datasets, and 
analytical tools can provide the information necessary to conserve ungulate migration. Through our collective efforts to study the world's ungulate migrations, we recognize an urgent need for a global inventory of known migrations, including those extant and recently lost.

\section{New Technology, New Discoveries}

Ungulates migrate in response to resources that wax and wane with the seasons. In the tropics, species like kob, eland, and elephant track rainfall across vast grasslands in search of food or water. In temperate systems, many ungulates move between mountains and plains to escape the deep snows of winter and feed on high-quality forage in summer. Across the Arctic, migratory caribou and reindeer move hundreds of kilometers from the boreal forests across the snowcovered tundra to aggregate on their northern calving grounds just as plants are greening up. The sheer numbers of caribou on the calving grounds dilutes the toll from their wolf, bear and wolverine predators (4).

Powerful new methods have made it possible to map migrations with precision. Tracking devices that are small, affordable, and reliable are being deployed on many species, allowing movement data to be acquired hourly at $\sim 10$-meter resolution. Satellites can now provide remotely sensed data to characterize spring green-up, drought, or snow, at the same scale migrating animals make behavioral decisions. When animal tracks are overlaid on dynamic maps of the earth's seasonal resources they reveal diverse migratory behaviors, from long-distance movements across climatic gradients, to shorter elevational movements to access alpine habitats.

Recent discoveries span several continents. In 2014, a zebra migration was discovered that stretches $500 \mathrm{~km}$ across Namibia and Botswana, a new record for the species (5). In 2016, in the 
Greater Yellowstone Ecosystem, mule deer were found to travel as far as $400 \mathrm{~km}$ one way (6). On the Mongolian Steppe, gazelle were found in 2018 to explore an area roughly the size of Hungary $\left(100,000 \mathrm{~km}^{2}\right)$ over their lifetime (7). Most recently, in Ethiopia's Gambella National Park, researchers discovered that white-eared kob migrate in an $860 \mathrm{~km}$ circuit connecting to the Boma-Bandingilo migration in South Sudan, extending the known migratory range (8). Altitudinal migrations are also being revealed across the world's mountain ranges. These short migrations allow animals to exploit highly variable habitats and derive functional benefits similar to long-distance migrations.

There is growing recognition that migratory behavior must be learned by mammals. In North America for example, migratory bighorn sheep and moose failed to migrate when first translocated into novel landscapes. Over multiple generations, however, individual populations gained knowledge to move and find forage, and they became more migratory (9). Sustained by spatial memory, migratory behavior may often exist as a type of animal culture that must be learned and transmitted between generations. The reliance on culture carries a stark warning for conservation, namely that the persistence of a given migration corridor depends on the survival of individuals that possess the knowledge to make it.

\section{Migrations in Danger}

The world's landscapes are changing rapidly, and unlike migratory birds, ungulates cannot fly over patches of unsuitable habitat. Instead, they must share the landscape with humans, making them especially vulnerable to land-use changes that impede their movements. Recent estimates project that we will build 25 million km of new roads across the globe by 2050 (10), with 
associated constraints on animal movement. The sheer scale of these developments casts a long shadow over the future of terrestrial migrations.

Impermeable barriers have long restricted the free movement of migratory herds. For example, nomadic movements of Mongolian gazelles are now constrained by railroads and border fences (7). In Botswana, veterinary fences built in the 1950s caused the death of hundreds of thousands of wildebeest. In the western U.S., highways have severed pronghorn and mule deer migrations (11). In Russia's Kola Peninsula, the construction of a railroad divided the wild reindeer population and eliminated the longest of the region's migrations. And in Europe, red deer must navigate a landscape shaped by centuries of human settlement, exploiting seasonal cycles of forage only in the most remote habitats.

Semipermeable barriers like unfenced roads, some fences, dwellings, and energy extraction are also increasing. Although animals may be able to pass through such impacted landscapes, their altered movements are often mismatched with patterns of rainfall or snowmelt. In the most extreme cases, migrations can be lost simply because the costs of navigating human-altered landscapes outweigh the benefits of migrating.

Climate change is an additional challenge. Many ungulates time their migrations to exploit patterns of plant green-up. Droughts are becoming commonplace, making it more difficult for animals to move in synchrony with green-up and access the best forage (12). Migratory ungulates are thus doubly challenged by a changing climate combined with barriers that prevent them from adjusting their movement tactics as conditions change. Protected areas rarely ease 
these challenges, because they remain too small to maintain the full sweep of resources needed to sustain most long-distance migrations.

Past landscape changes have taken their toll on ungulate migrations. Harris et al. (3) in 2009 described the loss of six out of 24 ungulate populations that make mass migrations. Historical accounts describe numerous migrations that no longer exist in the behavioral repertoire of current populations. The hundreds of thousands of Cape springbok that once traversed the Karoo landscape of South Africa were eradicated by fencing, disease, and hunting at the end of the $19^{\text {th }}$ century. In Kenya's Kajiado County, migrations of wildebeest, zebra and Thomson's gazelle have collapsed due to competition with livestock and massive land conversion. When we lost the tens of millions of bison that roamed North America, we lost the abundance necessary to sustain migration (2). Of the bison that now exist in small conservation herds, the Yellowstone population is one of a few that migrate.

When we lose the large herds of animals moving en masse across the landscape, we lose something else even more difficult to quantify. Such phenomena, the thundering of hooves kicking up dust as a herd moves across a vast landscape, remind us of the wildness that the Earth's habitats are still capable of supporting. Equally important are the cultural traditions and identity of many indigenous communities, such as the Inuit and Tlicho, whose livelihoods depend on migratory herds (13).

The movements of ungulates across the globe are more diverse and behaviorally complex than previously recognized. To maintain this diversity of movement, conservation of corridors and 
landscape connectivity has taken on new urgency. Unfortunately, efforts by wildlife managers and conservationists are thwarted by a singular challenge: Most ungulate migrations have never been mapped in enough detail to guide effective conservation.

\section{A Conservation Solution}

New methods now allow corridors to be mapped in detail from tracking data (14). When maps are overlaid on real landscapes, barriers and other threats can be identified, pointing the way to effective solutions. Migration maps are increasingly being used to target fences for removal, site overpasses and underpasses, guide energy leasing, and prevent housing development from blocking corridors. For species with high fidelity to corridors, such as mule deer (6), conservation may be achieved by targeted planning within corridors. For species that make nomadic or variable migrations, such as red deer, Mongolian gazelle, khulan, and barren-ground caribou, broader-scale strategies are needed to map and conserve their annual migrations and seasonal ranges. Regardless, mapping efforts to date illustrate that empirical tracking data can effectively guide efforts to conserve migrations.

We also need to inventory and map migrations that have already been lost, which is possible through indigenous, local, and expert knowledge. Mapping lost migrations can provide an important benchmark from which we can push back shifting baselines. For example, after a veterinary fence in Botswana that had blocked movements for 36 years was removed, zebra were recorded in 2004 making a nearly 600-km round trip migration similar to the one described in reports of historical sightings (15). In some South American rangelands, conservationists are hopeful that ranch abandonment will create opportunities to restore lost migrations of guanacos 
and huemul deer. We don't know which migrations can be restored, but mapping where they once existed is a necessary first step.

The Convention on Migratory Species (CMS) advanced conservation by formally recognizing animal migrations in 1979. Yet, tracking data have not existed in sufficient detail to map ungulate migrations until recently, which has constrained Parties to the Convention from developing concrete policies to protect migrations. We therefore propose a global atlas of ungulate migration, built from new and existing tracking studies. We envision a digital archive that translates tracking data into actionable migration maps that are standardized, in a central database, and publicly available. The atlas would be a resource for multiple stakeholders, such as indigenous peoples, local, regional, or national governments, and NGOs, to collaboratively manage shared landscapes to sustain known migrations while maintaining local livelihoods. Such an evidence-based effort is needed to assure that migrations - the actual paths that herds have used for hundreds or thousands of years - are incorporated into land management plans, environmental impact assessments, mitigation activities, and reserve designs. The atlas will also facilitate international coordination to protect transboundary movements and inform the development work of International Finance Institutions.

This will require dedicated collaboration on a global scale. Fortunately, tracking datasets are growing each year, and existing data can be analyzed now to begin an archive of detailed migration maps. Migrations that remain unmapped can be targeted for new field studies. To coordinate this effort, we have created the Global Initiative for Ungulate Migration (GIUM). The GIUM brings together scientists, conservationists and wildlife managers around the world to 
create a collaborative knowledge base of ungulate migrations, develop a global atlas, and spark new conservation and policy.

No doubt current and future generations will continue to be amazed by the annual treks of wildebeest across the Serengeti. We must now turn our research and conservation efforts to other species, such as the saiga and khulan in central Asia, the Arctic caribou and reindeer across North America and Eurasia, the moose in Scandinavia, and the guanaco and huemul in South America, to name just a few. Such an ambitious atlas brings hope that new migration maps can guide where we build roads, fences, and other infrastructure, and where we decide to forego such developments to safeguard the movement of animals. Through global collaboration, we can now assemble the knowledge, data, and tools necessary to maintain the wild and intact landscapes that migratory ungulates require and sustain the ecosystems supported by their abundance. 


\section{References and Notes:}

1. J. M. Fryxell, J. Greever, A. Sinclair, Why are migratory ungulates so abundant? American Naturalist 131, $781-798$ (1988).

2. C. Geremia et al., Migrating bison engineer the green wave. Proceedings of the National Academy of Sciences 116, 25707-25713 (2019).

3. G. Harris, S. Thirgood, J. G. C. Hopcraft, J. P. Cromsigt, J. Berger, Global decline in aggregated migrations of large terrestrial mammals. Endangered Species Research 7, 5576 (2009).

4. A. Bergerud, Evolving perspectives on caribou population dynamics, have we got it right yet? Rangifer 16, 95-116 (1996).

5. R. Naidoo et al., A newly discovered wildlife migration in Namibia and Botswana is the longest in Africa. Oryx 50, 138-146 (2016).

6. H. Sawyer, A. D. Middleton, M. M. Hayes, M. J. Kauffman, K. L. Monteith, The extra mile: Ungulate migration distance alters the use of seasonal range and exposure to anthropogenic risk. Ecosphere 7, e01534 (2016).

7. D. Nandintsetseg et al., Challenges in the conservation of wide-ranging nomadic species. Journal of Applied Ecology 56, 1916-1926 (2019).

8. A. Kassahun, "Movement ecology and home ranges of White eared kob (Kobus kob leucotis) in the Boma-Gambella transboundary landscape between the Republic of South Sudan and Ethiopia," thesis, Addis Ababa University, Ethiopia (2019).

9. B. R. Jesmer et al., Is ungulate migration culturally transmitted? Evidence for social learning from translocated animals. Science 361, 1023-1025 (2018).

10. W. F. Laurance et al., A global strategy for road building. Nature 513, 229-232 (2014).

11. M. J. Kauffman et al., Wild Migrations: Atlas of Wyoming's Ungulates. (Oregon State University Press, Corvallis, OR, 2018).

12. E. O. Aikens et al., Drought reshuffles plant phenology and reduces the foraging benefit of green-wave surfing for a migratory ungulate. Global Change Biology 26, 4215-4225 (2020).

13. A. Cunsolo et al., "You can never replace the caribou": Inuit experiences of ecological grief from caribou declines. American Imago 77, 31-59 (2020).

14. A. D. Middleton et al., Conserving transboundary wildlife migrations: recent insights from the Greater Yellowstone Ecosystem. Frontiers in Ecology and the Environment 18, 83-91 (2020).

15. H. Bartlam-Brooks, M. Bonyongo, S. Harris, Will reconnecting ecosystems allow longdistance mammal migrations to resume? A case study of a zebra Equus burchelli migration in Botswana. Oryx 45, 210-216 (2011). 
Acknowledgments: We are grateful to Emilene Ostlind and Greg Nickerson for reading early drafts; Julia Olson for cartography; Ken Lay for early discussions about GIUM; Ralph Buij for vulture data; and the Government of the Northwest Territories for caribou data. Work in Kenya supported by the Director of the Directorate of Resource Surveys and Remote Sensing. Work in Zimbabwe supported by the Director General of the Zimbabwe Parks and Wildlife Management Authority, the Zone Atelier LTSER program, and H. Fritz. Red deer data provided by the Euromammals and Euroreddeer initiatives. Work of DP carried out under State Order №02182019-0080. Base maps sourced from ESRI, Natural Earth and Open Street Map. Funding: The GIUM is financially supported by the Knobloch Family Foundation, George B. Storer Foundation, and the Bole and Klingenstein Foundation. Field studies funded by European Union's Horizon 2020 research and innovation program \#641918 (AfricanBioServices), French 'Agence Nationale de la Recherche' \#ANR-16-CE02-0001-01, German Federal Ministry of Education and Research (MORESTEP, \#01LC1710A and \#01LC1820A), Hawk Mountain Sanctuary, NASA \#NNX15AW71A, NSF LTREB \#1556248, NSF DBI1915347, NSF DEB9903416, NSF DEB-0343960, NSF DEB-1020479, The Peregrine Fund, Princeton University, and the Robert Bosch Foundation. Author contributions: MJK, FC, SCJ, MH, JGCH, JAM, TM, AM, WP and CR conceived of the study and wrote the original manuscript; MJK, SCJ, JGCH, TM, KA, JA, ND, CF, AG, CJK, SM, TAM, KAO, CP, HS, AT, and MZV collected the data; MJK, AS, JEM and EG designed the maps. All others reviewed and edited the manuscript. 


\section{Migration underpins terrestrial ecosystems}

The annual migration of 1.3 million wildebeest, plus several hundred thousand zebra, gazelle, and eland, influence ecological dynamics in the Serengeti ecosystem, including positive feedback loops on grassland productivity. This mass migration of herbivores supports a diverse predator and scavenger community that tracks their year-round movements.

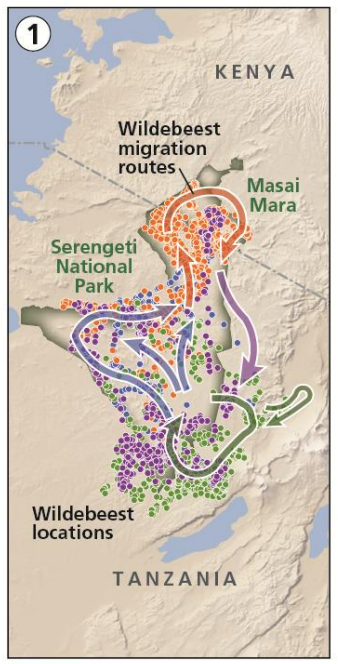

1 Wildebeest migration GPS locations for several wildebeest moving between the dry (orange) and wet season (green) illustrate the generalized migration route.

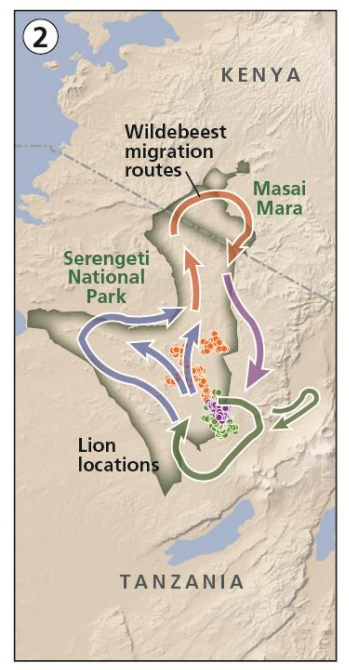

2 Lion movements Despite being tied to their home ranges, lion prides follow the seasonal flux of ungulate prey (GPS locations illustrate the year-round track of one lion).

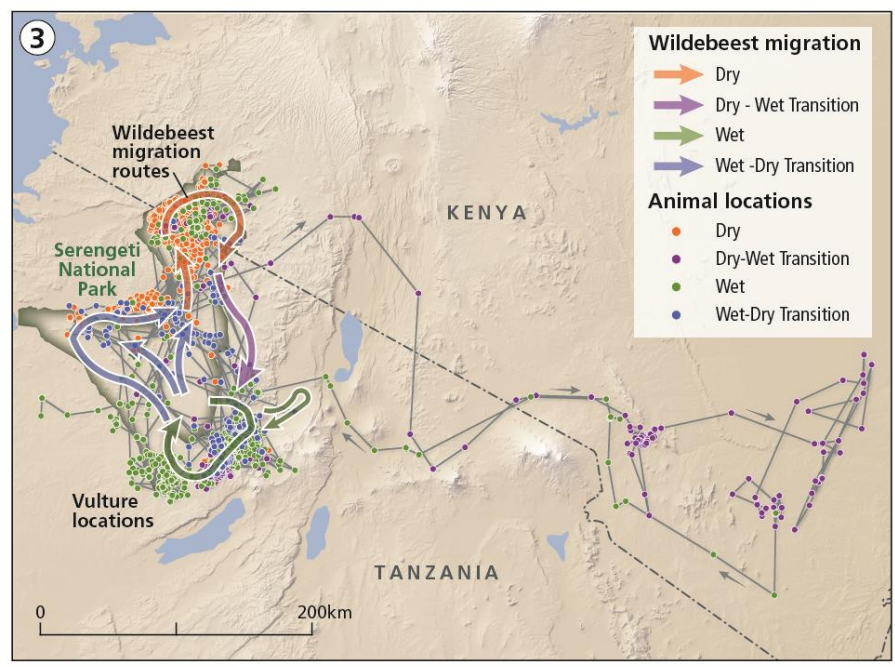

\section{Vulture movements}

Several species of vultures scavenge extensively on the carcasses

of migratory wildebeest, synchronizing their movements to the $d r y$

season range from hundreds of kilometers away. The track of a

lappet-faced vulture is shown, along with the more wide-ranging

movements to the east of a white-backed vulture.

Fig. 1. Migration underpins terrestrial ecosystems. The annual migration of 1.3 million wildebeest, plus several hundred thousand zebra, gazelle, and eland, influence ecological dynamics in the Serengeti ecosystem, including positive feedback loops on grassland productivity. This mass migration of herbivores supports a diverse predator and scavenger community that tracks their year-round movements.

\section{Wildebeest migration}

GPS locations for several wildebeest moving between the dry (orange) and wet season (green) illustrate the generalized migration route.

\section{Lion movements}

Despite being tied to their home ranges, lion prides follow the seasonal flux of ungulate prey 
(GPS locations illustrate the year-round track of one lion).

\section{Vulture movements}

Several species of vultures scavenge extensively on the carcasses of migratory wildebeest, synchronizing their movements to the dry season range from hundreds of kilometers away. The track of a lappet-faced vulture is shown, along with the more wide-ranging movements to the east of a white-backed vulture. 


\section{Ungulate migrations around the world}

Animal tracking studies are being conducted around the world, facilitating discovery of previously unknown movements and making it possible to map migration and identify threats with precision.
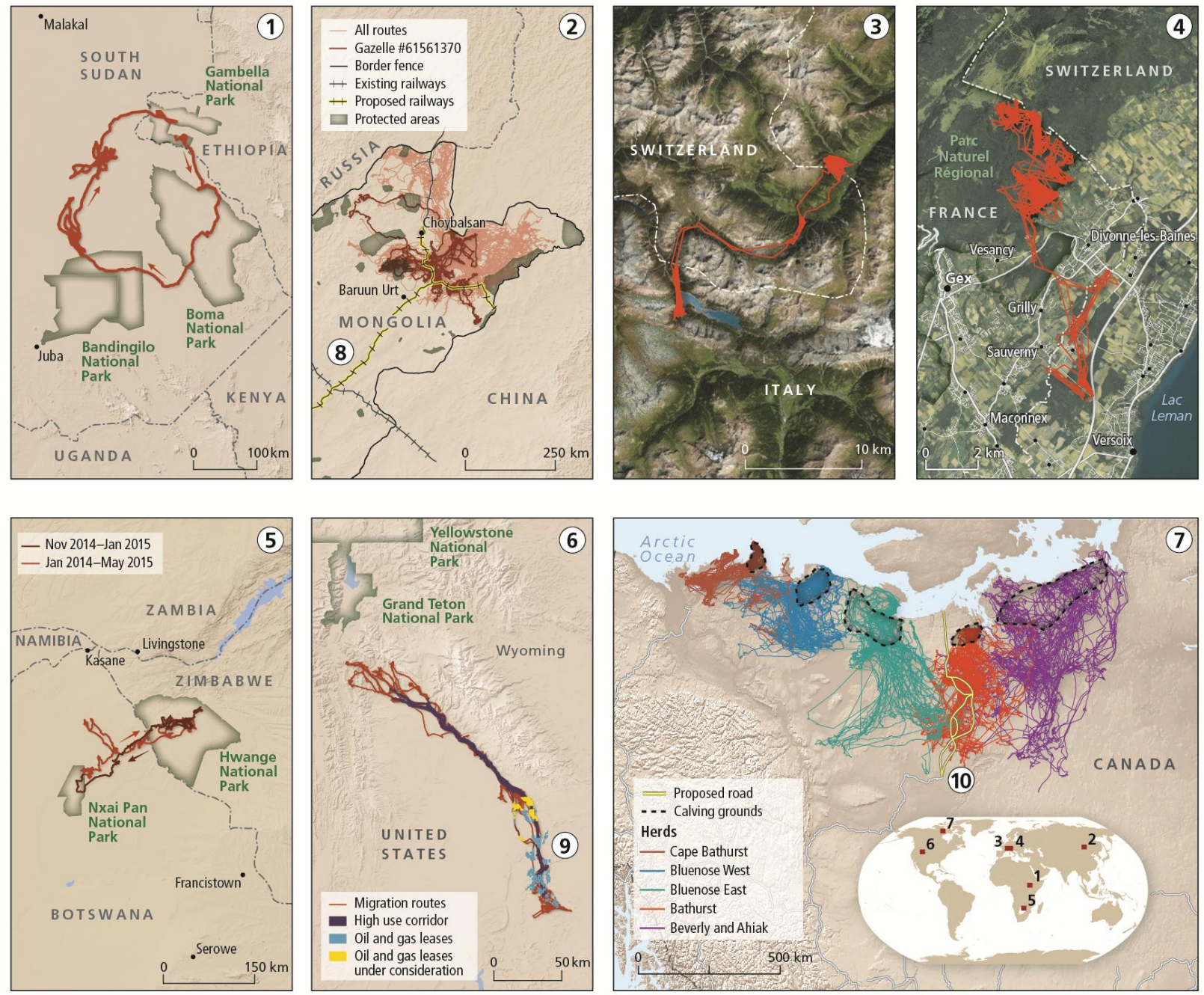

\section{White-eared kob}

In 2018, white-eared kob were discovered to make an $860-\mathrm{km}$ migratory circuit between Ethiopia and South Sudan, extending the known migratory range (8). The herds traverse oil and gas concessions, hotspots of armed conflict, and commercial agricultural developments in the Boma-Gambella landscape.

\section{Mongolian gazelle}

On the Central Asian steppe, the nomadic movements of Mongolian gazelle are an order of magnitude larger than the region's protected areas.

\section{Red deer, European Alps}

In remote habitats, red deer are still able to fully exploit the abundance of seasonal forage by migrating across mountain ranges.

\section{Red deer, semi-urban}

Animals living near human population centers may try to maintain migration, but their movements are often constrained and truncated by human settlements.

\section{African elephants}

Elephants leave Botswana and make a transboundary migration across unprotected areas to find permanent surface-water in their dry season range in Zimbabwe.

\section{Wyoming mule deer}

A 242-km mule deer migration was discovered in Wyoming in 2014, traversing a mix of public and private lands.

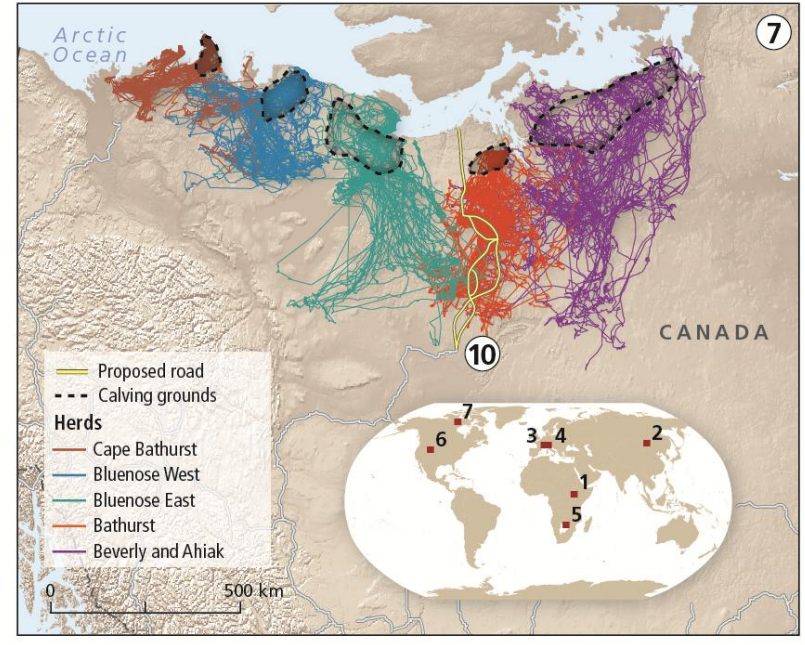

7 Barren-ground caribou In the Northwest Territories and Nunavut, caribou range over vast areas of Arctic tundra and boreal forest before converging to give birth on herd-specific calving ranges near the coast.

\section{$8 \mathrm{~A}$ proposed railroad}

The annual movements of Mongolian gazelle are bound by impermeable border fences with Russia and China. A proposed railroad threatens to further constrain their large nomadic movements.

\section{Oil and gas development} Researchers analyzed tracking data (14) to delineate a high-use corrido (dark blue) from individual routes (orange). The corridor was formally designated by State wildlife officials in 2016, allowing the corridor to be considered during recent oil and gas leasing decisions.

\section{$10 \mathrm{~A}$ proposed road}

Migration tracking data is being used to evaluate proposed alternatives for an all-season road (yellow line) that would cut through the post-calving, summer and winter range of the Bathurst herd, which has declined $97.5 \%$ since 2000. 
Fig. 2. Ungulate migrations around the world. Animal tracking studies are being conducted around the world, facilitating discovery of previously unknown movements and making it possible to map migration and identify threats with precision.

\section{White-eared kob}

In 2018, white-eared kob were discovered to make an 860-km migratory circuit between Ethiopia and South Sudan, extending the known migratory range (8). The herds traverse oil and gas conces- sions, hotspots of armed conflict, and commercial agricultural developments in the Boma-Gambella landscape.

\section{Mongolian gazelle}

On the Central Asian steppe, the nomadic movements of Mongolian gazelle are an order of magnitude larger than the region's protected areas.

\section{Red deer, European Alps}

In remote habitats, red deer are still able to fully exploit the abundance of seasonal forage by migrating across mountain ranges.

\section{Red deer, semi-urban}

Animals living near human population centers may try to maintain migration, but their movements are often constrained and truncated by human settlements.

\section{African elephants}


Elephants leave Botswana and make a transboundary migration across unprotected areas to find permanent surface-water in their dry season range in Zimbabwe.

\section{Wyoming mule deer}

A 242-km mule deer migration was discovered in Wyoming in 2014, traversing a mix of public and private lands.

\section{Barren-ground caribou}

In the Northwest Territories and Nunavut, caribou range over vast areas of Arctic tundra and boreal forest before converging to give birth on herd-specific calving ranges near the coast.

\section{A proposed railroad}

The annual movements of Mongolian gazelle are bound by impermeable border fences with Russia and China. A proposed railroad threatens to further constrain their large nomadic movements.

\section{Oil and gas development}

Researchers analyzed tracking data (14) to delineate a high-use corridor (dark blue) from individual routes (orange). The corridor was formally designated by State wildlife officials in 2016, allowing the corridor to be considered during recent oil and gas leasing decisions.

\section{A proposed road}


Migration tracking data is being used to evaluate proposed alternatives for an all-season road (yellow line) that would cut through the post-calving, summer and winter range of the Bathurst herd, which has declined $97.5 \%$ since 2000.

Fig. 3. A group of pronghorn pause during their spring migration to navigate a fence that bisects their migration corridor (photo by Joe Riis).

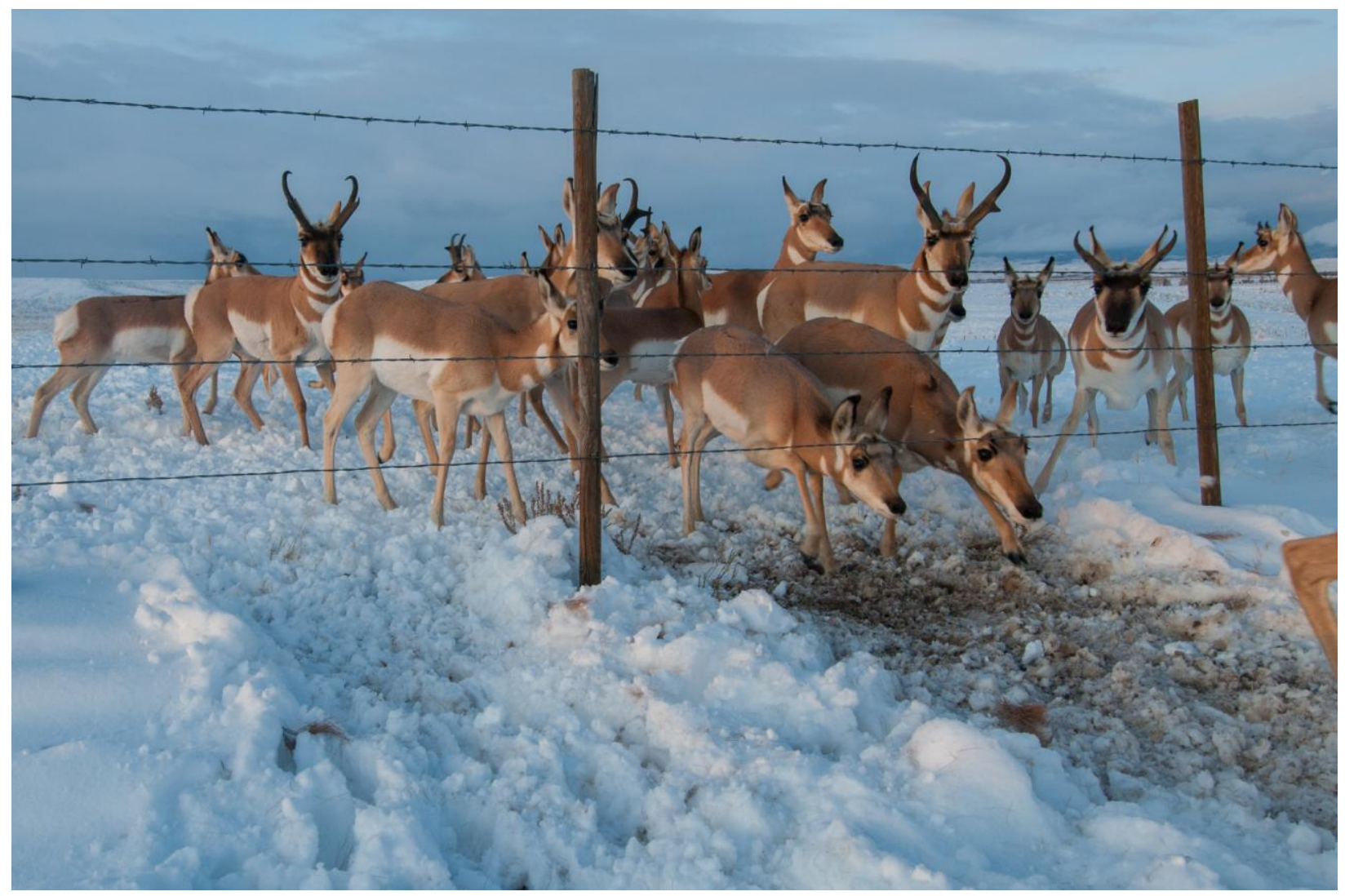

